\title{
LA IMPORTANCIA DEL GÉNERO EN LAS REPRESENTACIONES Y ACTITUDES EN MATERIA DE ARTE. UN ESTUDIO CUALITATIVO
}

\author{
Asier Amezaga Etxebarria \\ Universidad del País Vasco / Euskal Herriko Unibertsitatea \\ Javier Rujas Martínez-Novillo ${ }^{1}$ \\ Universidad Complutense de Madrid
}

\begin{abstract}
Resumen: El presente artículo analiza la importancia del género en la configuración de las representaciones y actitudes con respecto al arte en estudiantes universitarios a partir de una investigación exploratoria con grupos de discusión. Estudiando los distintos temas, oposiciones y posicionamientos que emergen en los discursos, y el tipo de relación con el arte que manifiestan, constata que hombres y mujeres comparten un mismo universo simbólico común en materia de arte, si bien pueden encontrarse diferencias sutiles de grado o intensidad atribuibles al género pero irreductibles a bloques homogéneos y radicalmente opuestos. El análisis de las estructuras incorporadas de percepción y apreciación de los agentes abre así la puerta a una mejor comprensión de las desigualdades de género en materia de arte y cultura, y de los complejos mecanismos que contribuyen a su reproducción.
\end{abstract}

Palabras clave: sociología del arte, género, representaciones, grupos de discusión

\section{The importance of Gender in representations and attitudes towards art. A qualitative study}

Abstract: This paper analyzes the importance of gender in the shaping of representations and attitudes towards art among university students, on the basis of an exploratory research with focus groups. Examining the issues, oppositions and positions that emerge in discourses, and the kind of relation to art they show, we state that men and women share the same symbolic universe concerning art. Although subtle differences of degree or intensity are found which can be attributed to gender, these differences cannot be reduced to homogeneous and radically opposed blocks. The analysis of agent's incorporated structures of perception and appreciation opens the way to a better understanding of gender inequalities in art and culture and of the complex mechanisms that contribute to their reproduction.

Keywords: sociology of art, gender, representations, focus groups

Los rechazos importan tanto como las admiraciones, los profanos tanto como los iniciados, el mal gusto tanto como el bueno, y las personas tanto como las obras.

Nathalie Heinich (2003)

\footnotetext{
${ }^{1}$ En la actualidad, becarios del Programa de Formación del Profesorado Universitario (FPU) del Ministerio de Educación. Queremos agradecer a Fátima Arranz su apoyo y orientación en la realización de esta investigación, a Alicia Flórez el apoyo en la moderación de los grupos y a los participantes en los mismos su valiosa colaboración. También agradecemos a Rafael García Alonso su lectura y comentarios.
} 


\section{INTRODUCCIÓN}

En el curso 2008/2009, según el Instituto de la Mujer, el 65,4\% de las personas matriculadas en la Licenciatura en Bellas Artes eran mujeres, una proporción superior al $59,77 \%$ de mujeres matriculadas en el conjunto de licenciaturas ${ }^{2}$. Sin embargo, de acuerdo con los datos publicados por la Associació d'Artistes Visuals de Catalunya, en 2003 sólo un $31,3 \%$ de las artistas eran mujeres, una proporción inferior al 39,4\% de mujeres que formaban parte de la población ocupada ese año (AAVC, 2006: 46). Datos del último trimestre de 2009 de la Encuesta de Población Activa, apuntan en la misma dirección al señalar que las mujeres representan un $36,8 \%$ de las personas activas en Actividades de creación, artísticas y espectáculos, mientras que representan un $44,14 \%$ de la población activa en su conjunto ${ }^{3}$. La asociación Mujeres en las Artes Visuales, por su parte, constata el reducido número de mujeres artistas que recibe un reconocimiento institucional (MAV, s.f.).

De un modo general, puede por tanto afirmarse que aunque las mujeres tiendan a mostrar mayor interés por las actividades artísticas y culturales ${ }^{4}$, iniciando en mayor número que los hombres una formación artística, la actividad artística sigue copada por los hombres, que son además los que alcanzan un mayor nivel de consagración. En otros términos, se trata de dos formas combinadas de segregación (Harding, 1986: 63 y ss.): una segregación horizontal, que atrae a las mujeres hacia un sector -en este caso el artístico, y una segregación vertical, que hace que la profesionalización y consagración, las posiciones de mayor reconocimiento en el campo artístico estén prácticamente monopolizadas por los hombres ${ }^{5}$.

El trabajo de investigación cuyos resultados presentamos a continuación busca contribuir a la comprensión de esta desigualdad centrándose en el análisis de las representaciones y actitudes que hombres y mujeres manifiestan con respecto al arte. Para ello, se sitúa en el cruce de dos subdisciplinas de la sociología: la sociología del arte y la sociología de las relaciones de género. Ambas disciplinas se han desarrollado de manera independiente y estableciendo pocos vínculos entre sí. La presente investigación nace precisamente de la intención de relacionar ambas empíricamente.

\footnotetext{
${ }^{2}$ Instituto de la Mujer, Estadísticas. Educación. Alumnado Universitario II. Licenciaturas. Alumnado matriculado, disponible en www.inmujer.es (última consulta: 3 de enero de 2012).

${ }^{3}$ INE, Encuesta de Población Activa. Resultados detallados. Activos por sexo y rama de actividad, disponible en www.ine.es (última consulta: 3 de enero de 2012).

${ }^{4}$ Un estudio del Injuve revela un interés mayor de las mujeres jóvenes por actividades relacionadas con el arte que el de los hombres de la misma edad. En la pregunta por las actividades de tiempo libre que les gusta hacer a los jóvenes de 15 a 29 años, las mujeres presentan una mayor inclinación por las actividades artísticas y culturales: el $87,7 \%$ de las mujeres encuestadas señala que le gusta ir al cine, frente al $81,1 \%$ de los hombres; el $47,4 \%$ ir al teatro, frente al 32,4\%; el 78,4\% ir a conciertos, frente al 70,2\%; el 96,9\% escuchar música, CDs, cintas, frente al $95,1 \%$; el $45,8 \%$ ir a museos, exposiciones, frente al $36,1 \%$; el $70,1 \%$ leer libros, frente al 53,7\% (Injuve, 2007: 10).

${ }^{5}$ Para una mayor precisión convendría tener en cuenta la diferenciación interna del mundo del arte, analizando qué sectores o subcampos dentro del campo artístico son los más feminizados y comprobando si en todos ellos las posiciones de mayor status son ocupadas por hombres.
} 
En este sentido, este trabajo se inscribe en la línea de los trabajos desarrollados por Pierre Bourdieu - por separado - tanto en materia de arte y cultura (2006 [1988], 1995) como en materia de género (1998). Recurrimos también a las aportaciones fundamentales de la crítica feminista sobre la construcción de subjetividades diferenciadas en cuanto al género (Meyer, 2001) y sobre la relación del género con el arte (Mayayo, 2003), tema que, en ciencias sociales, parece haberse desarrollado sobre todo de forma teórica dentro del feminismo. Sin embargo, si estas aportaciones han señalado el carácter masculino y androcéntrico del mundo del arte (cerrado a las mujeres e injusto con el reconocimiento de las artistas, invisibilizadas), la reproducción de la diferencia entre sexos a través de la historia del arte o la relegación del "arte femenino" a categoría negativa que "sustenta el privilegio masculino" (Mayayo, 2003: 51-52), no parece haberse estudiado la relación concreta entre la producción social de un habitus o un tipo de subjetividad diferenciada según el género y las diferentes formas de representarse y valorar el arte, de relacionarse con él, en hombres y mujeres.

Desplazando por tanto la atención de la investigación sobre el gusto en materia de arte de las diferencias socialmente construidas entre clases sociales (Bourdieu, 2006 [1988]) a las diferencias socialmente construidas entre sexos (disposiciones, subjetividades diferenciadas), nos planteamos estudiar de forma empírica la relación entre el género y las representaciones y actitudes de los sujetos en relación al arte. Los resultados que aquí presentamos se basan en un trabajo de campo cualitativo, basado en dos grupos de discusión realizados con estudiantes universitarios de la facultad de Ciencias Políticas y Sociología de la Universidad Complutense de Madrid durante el curso 2008$2009^{6}$. Limitado a este sector de la población y limitado en cuanto al número de grupos realizados, este estudio debe considerarse como un trabajo exploratorio que deja abierta una línea de investigación que debiera ser ampliada a otros sectores sociales y contrastada con un mayor número de grupos.

Sin embargo, permite ya observar la complejidad de la relación entre el género y las formas de representarse el arte y relacionarse con él, y constatar que las diferencias entre hombres y mujeres en este sentido tienen que ver más con diferencias sutiles de intensidad, de matiz, que con discursos y subjetividades radicalmente distintos. Hombres y mujeres comparten un mismo universo simbólico (Berger y Luckmann, 2006 [1967]) en materia de arte, pero difieren en la forma de posicionarse y construir su relación con el arte.

En un primer momento analizaremos las principales representaciones y actitudes frente al arte producidas en los grupos de discusión en dos partes, tomando como hilo conductor los dos grandes temas que organizaron los discursos producidos: primero, el arte contemporáneo y su relación con el problema de definición del arte; segundo, la perversión del arte por las élites, el mercado y las masas. En la tercera parte, nos centraremos en las formas de

\footnotetext{
${ }^{6}$ En el diseño de los grupos seguimos el criterio de heterogeneidad inclusiva (Ibáñez, 2003: 275-276): la homogeneidad de los grupos la daría fundamentalmente el género, variable central del estudio, admitiéndose cierta heterogeneidad relativa en cuanto a la edad (estudiantes entre primer y cuarto curso de carrera, entre 18 y 24 años), la formación (Trabajo Social, Ciencias Políticas, Sociología, Antropología) y la clase social (siendo conscientes de que la universidad es una institución frecuentada principalmente por estudiantes procedentes de las clases medias).
} 
posicionarse frente al arte y formas de relación con el arte que los sujetos manifestaron en sus discursos.

\section{LA CUESTIÓN DEL ARTE CONTEMPORÁNEO Y EL PROBLEMA DE DEFINICIÓN DEL ARTE}

En el curso de los grupos de discusión, el arte contemporáneo apareció como una de las referencias fundamentales de la discusión. El mero hecho del recurso a este tema muestra ya la penetración en el sentido común y los discursos ordinarios de los "profanos" de un debate harto conocido en ámbitos eruditos, intelectuales y artísticos: el de la crisis del arte "moderno" o "contemporáneo". En particular, en los grupos de discusión este tema -un recurso "fácil" por su amplia cobertura mediática - se ve desarrollado a través de varios motivos o subtemas que vienen a plantear el problema de fondo que se encuentra tras este debate reapropiado por los profanos: el problema de la definición del arte legítimo, de aquello que puede ser considerado o no arte.

A la hora de definir en qué consiste el arte, en los grupos se recurre con frecuencia a la contraposición, expresada con términos variables y más o menos confusos, entre el arte contemporáneo y el "antiguo". Esta oposición estructura claramente los discursos tanto de chicos como de chicas pese a que se empleen términos distintos con ciertos matices. Así, se emplea el término "arte moderno" o "modernista" para referirse al arte actual —no al de la edad moderna-, en contraposición con el antiguo o clásico, que identifican con todo el arte anterior y cuya legitimidad aparece incuestionada -y cuyas referencias más emblemáticas (recurrentes en los grupos) serían Goya, Velázquez (Las meninas) o Picasso. Al énfasis en su carácter actual se suma lo que emerge en los grupos como característica definitoria fundamental de este arte "moderno", asociado en los grupos a las vanguardias de principios del siglo XX y en buena medida a todo lo que viene después: la ruptura con el pasado o con el orden moral, la trasgresión de la "norma" y la "moda" en la búsqueda continua de la originalidad y la innovación.

Sin embargo, el tema de la ruptura también parece suscitar controversia al versar sobre todo sobre la cuestión del arte contemporáneo y su crisis actual. Los grupos coinciden en su diagnóstico común de la situación actual del arte al señalar que el arte contemporáneo ha llegado a un punto de saturación que dificulta la definición. En particular, denuncian que se ha llegado a un punto en el que ya no hay más que repetición de las mismas obras:

Llevamos años y años viendo una y otra vez los mismos libros y los mismos libros y los mismos libros y los mismos libros. Ya desde los años 70 hasta aquí, todo está siendo igual. $\left(\mathrm{GDH}^{7}\right)$

En la misma línea, las chicas señalan el hartazgo frente a esa repetición de lo mismo insistiendo en la conversión en norma de lo pretendidamente rupturista:

...ya estamos en el siglo XXI, ha pasado un siglo y ya estamos un poco cansados de ver váteres ${ }^{8}$ y de ver cadáveres en formol ${ }^{9}$, vaya...

\footnotetext{
${ }^{7}$ En adelante escribiremos GDH cuando se trate del grupo de discusión de chicos y GDM cuando se trate del de chicas.
} 
Sí, sí. Entonces, ¿está todo inventado? Pues ése es el problema. (GDM)

En el desarrollo de los grupos de discusión, estas posiciones son negociadas y matizadas, en la medida en que se abren ciertos resquicios para elementos novedosos ("Está todo escrito, pero en las formas hay muchas variaciones"). Al tiempo que se considera que las obras actuales han perdido la novedad, redundando continuamente en lo mismo, implícitamente se asume la importancia y centralidad de la innovación vanguardista en el arte, así como la existencia de posibilidades de renovación del arte, combinando fatalismo y esperanza.

En relación con este diagnóstico marcadamente pesimista, encontramos también en los grupos la idea de un arte sumido en el relativismo:

Cualquier cosa ya puede ser arte, vaya (GDH)

A estas alturas ya todo es una cuadro, todo es un... (GDM)

Además, en los grupos se recurre a la exageración, la ironía o la ridiculización del arte contemporáneo para ilustrar este diagnóstico y posicionarse de forma crítica ante esta situación de relativismo que, para ellos y ellas, desemboca en lo absurdo:

Un pelo sobre una mesa es arte, ¿no?

La lata de Warhol en su momento [...] Pero, ahora yo cojo una lata de Gallina Blanca, yo que sé, y es que... (GDM)

El Warhol. ¿Eso es arte? Es una foto a una lata de tomate. (GDH)

En ambos grupos surgen ejemplos paradigmáticos de lo que consideran este arte: el museo Reina Sofía y la célebre Feria Internacional de Arte Contemporáneo (ARCO), ambas referencias muy conocidas, presentes en los medios de comunicación de masas y con frecuencia objeto de polémicas por el tipo de obras que acogen. Además, en los grupos se asocia de forma análoga al arte contemporáneo y a la idea del "eso lo hago yo" (sic) o el "eso lo hace cualquiera" $(\mathrm{sic})^{10}$ una misma representación estereotipada de una obra: "un punto negro sobre un lienzo blanco" (GDH); "un punto rojo" (GDM).

Por otro lado, aunque las chicas defienden esta idea de falta de criterio del arte actual, también aparecen posiciones que matizan esta tesis, que sin embargo aparece como incuestionable en el caso de los chicos. Con una actitud menos rotunda y más comprensiva con respecto al arte actual, también abren una línea argumental en defensa del propósito de "fondo" de este arte. No es lo absurdo por lo absurdo, tiene una idea de fondo:

\footnotetext{
${ }^{8}$ Se refiere a la conocida obra Fontaine (1917) del francés Marcel Duchamp, consistente en un urinario con una pequeña inscripción.

${ }^{9}$ Se refiere en este caso a la célebre obra La imposibilidad física de la muerte en la mente de alguien vivo del británico Damien Hirst, consistente en un "tiburón de algo más de cuatro metros de longitud, suspendido en un tanque transparente de aldehído fórmico" (El Mundo, 29/06/2006).

${ }^{10}$ Este tópico enlaza con la idea desarrollada por Walter Benjamin (1973 [1935]) de que la posibilidad de reproducción de la obra hace que ésta pierda su "aura", su carácter único que posibilita la experiencia estética.
} 
Es que yo creo que el arte moderno lo que intenta es como abrir la mente, ¿sabes? (GDM)

Esta actitud se desarrolla en relación con la idea de que una obra de arte es comprensible si se dispone de la clave para entender su significado (Ver tercera parte).

Sin embargo, al mismo tiempo que se mantiene una actitud de defensa ortodoxa del arte legítimo (reconocido y consagrado, frente al vanguardista), se mantiene en los grupos una visión heterodoxa que afirma la relevancia del contexto social e histórico en la definición del arte (probablemente relacionada con la propia formación en disciplinas de ciencias sociales de todos los participantes):

Cuando Picasso hizo su cuadro la gente diría que está mal dibujado, igual que tú dices que está mal escrito. (GDH)

Sí, pero a lo mejor para la época, Saturno devorando a sus hijos a lo mejor sí que representaba lo mismo. Ahora, para nosotros, lo que para nosotros es moderno, arte moderno [gesto de hacer comillas], dices "esto es una tontería". Pero dentro de, yo que sé, cincuenta años dirán: “¡Bueno! ¿Cómo no podías entender esto?”, ¿sabes? (GDM)

Vemos, por tanto, que si la crisis del arte en la actualidad parece suscitar acuerdo en los grupos, los matices y las diferencias sutiles en los discursos de chicos y chicas introducen una mayor complejidad y una menor coherencia de los discursos que éstos construyen sobre el arte.

\section{LA PERVERSIÓN DEL ARTE: ÉLITES, MERCADOS Y MASAS}

En esa búsqueda de una definición del arte, los grupos señalan qué no es arte, poniendo sobre la mesa procesos y situaciones que impedirían, según ellos, su realización: la masificación y la mercantilización. Tratan así además de rentabilizar los conocimientos que tienen en el campo de las ciencias sociales extrapolándolas al campo artístico: hablan del campo artístico como un campo elitista. Estos aspectos esconden una cuestión de fondo que une concepciones diferentes del ideal de democratización que todos dicen profesar.

\section{Masificación y mercantilización}

Masificación y mercantilización aparecen en los grupos como procesos que parecen impedir la manifestación artística. Chicos y chicas se posicionan de manera diferente frente a ambos procesos, poniendo énfasis en uno u otro.

Entre las chicas el arte masificado aparece en ocasiones como perversión del arte. Cuando hablan de este fenómeno emplean términos como "todo el mundo", "el público", "la gente", "borregueo", "masa" (sic). Usan la tercera persona y la segunda persona del singular contraponiéndolas al yo, para distanciar a los sujetos hablantes de ese público y ridiculizar las prácticas de la "masa", protegiendo su propia posición y produciendo al mismo tiempo la imagen de un público homogéneo, informe e irreflexivo: 
[Hablando de La Noche en Blanco que se organiza en Madrid] ¿Para qué entiendo, si no has ido los miércoles o no sé qué día que es gratis, ¿por qué quieres ir hoy a las dos de la mañana? O sea es absurdo, es borregueo. Es masa, los niños allí lloviendo, las dos... Yo te juro que no salía de mi asombro. (GDM)

Lo primero que habría que preguntarse si la peña cuando compra lo que sea, una buena o una mala novela, un buen cuadro o uno malo, en realidad está pensando en arte o algo por el estilo, y si no está movida más bien por "me he pagado un viaje para ir a Berlín para ir en verano y tengo que ir al museo de tal, porque sino voy a parecer idiota". Que puede ser, yo en realidad no sé cuanta gente va por ahí planteándose qué es arte y qué no lo es. (GDH)

En el caso de las chicas, el consumo de arte aparece vinculado al objeto de consumo, mientras que en el de los chicos se vincula a la forma de consumirlo. Así, en el caso de las primeras un consumo masivo desvirtuaría la obra de arte, mientras que en el de los segundos la obra permanecería inalterable, pura, independientemente del uso que el público haga de la misma. La desvirtuación de la obra de arte a través del consumo profano es evocada en relación con el Pop art:

Bueno, ya es popular... y hay camisetas. Dices: Ya no impacta y en el momento que no impacta, pues... y en el momento que no impacta, no es vanguardia. (GDM)

La permisividad que observamos ante la masificación del arte por parte de los chicos no tiene lugar sin embargo en el caso de la mercantilización. Se valen de la parodia para significar la ausencia de objeto artístico de la obra mercantilizada:

Sí, yo creo que hoy en día el arte lo pone el mercado, o sea si se vende es arte. Mira los cuadros del... cómo se llama, el colgao este, el lata-detomate [...] el Warhol. ¿Eso es arte? Es una foto a una lata de tomate. Pero se vende, o sea es arte. (GDH)

Se valen del menosprecio para señalar la distancia entre el arte mercantilizado y "lo que debiera ser" arte, el arte puro y verdadero. Más que en la esencia del arte se incide en la definición social del arte, en este caso, la realizada por el mercado.

Desde la definición ideal del arte que presuponen, no tendría que darse esta concordancia entre mercado y arte, el segundo no debiera subordinarse al primero:

Pero, por eso, estamos repitiendo una y otra vez que no es arte todo lo que se vende, que no es arte todo lo que se demande como... [...] o cualquiera de Operación Triunfo. No es arte, por mucho que se demande y aunque tengan muchas más ventas que otro disco. (GDH)

La "perversión" del arte por el mercado es un elemento que aparece de forma recurrente. El arte pasa a convertirse en mercancía: pierde el valor de uso en pro de su valor de cambio. Por eso, la chica que "canta bien" -ejemplo que usan los chicos - "acabará pervertida" (sic): su don, cantar bien, se vuelve 
impuro, se pervierte. Por tanto, se sitúa el arte verdadero fuera del mercado. Desde este punto de vista, si el mercado es perversión, el arte propiamente dicho se ve obligado a realizar un ejercicio de purificación: los artistas deben romper "esos esquemas", la "publicidad general" (sic), etc. El arte auténtico se entiende así como ejercicio de escape, de liberación con respecto a los elementos profanos que lo pervierten.

En ambos grupos encontramos una argumentación contradictoria. Por un lado, se afirma la fatalidad de la perversión en el devenir del artista. Por otro, se afirma que lo puro es lo que permanece a lo largo del tiempo, lo que el paso de la historia no logra arrastrar al olvido ("son las cosas que quedan", sic).

De todos modos, este discurso se matiza conforme van saliendo posiciones contrarias, para señalar la posibilidad (o no) de convivencia de arte y mercado como algo más contingente:

Pero, dentro del poder que ahora mismo es el mercado, el poder fabrica y promueve expresiones artísticas, algunas de las cuales llegan a ser arte y otras que son abortos. (GDH)

Se identifican dos entes personalizados - "poder" y "mercado"— a los que se atribuye una capacidad de agencia. En este caso, el "mercado" produce arte, pero su producción puede convertirse en "un aborto", lo que implica siguiendo la metáfora biológica-que era un arte en embrión, en intención. Se admite que la intención puramente mercantil - no estética- del mercado puede coincidir con la creación de arte, aunque no sea su intención principal (vender).

En el caso de las chicas, coincidirían con la posición que matiza esa relación, y se volvería a poner énfasis en la obra de arte en sí, como objeto de juicio, al margen de las intenciones del artista:

Eso, yo creo que eso es una elección personal [tocar por dinero], o sea, que dices "hostia, pues... Otra cosa es que digas "Te has vendido y la calidad de tú música es una mierda". (GDM)

La calidad de la obra, si es o no arte, aparece como un elemento distinto que puede variar independientemente de la relación del artista con el mercado ("te has vendido"). Asimismo, en el desarrollo de la discusión se pone sobre la mesa la cuestión de la legitimidad de los artistas para vender su obra ("joder, que cada uno tiene que comer de lo suyo", sic).

¿Sabes lo que pasa? Que eso implica, eh, bien, una persona que está vendiendo su arte desde un punto de vista superhumilde, desde un punto de vista de "no, yo lo hago para los que de verdad quieren este tipo de música y tal". Y ese tipo de músico luego va derivando hacia lo que quieren los más... y se ha salido de esa línea, yo creo que ya es que se está dando...

Es que no representa. El público que le seguía, ya lo que sea de Melendi, su imagen, el marketing, lo que sea. No representa a ese público que tenía en un principio. (GDM)

Se denuncia, por un lado, al artista por lo que se considera una falta de honestidad (el venderse, el traicionar a su público), y, por otro, que el criterio de la mayoría, de la masa, acabe pervirtiendo la creación artística. En este caso, 
en lo que al mercado se refiere, el problema no se vincula al hecho de que la obra se configure como mercancía - como en el caso de los chicos-, sino al hecho de que el criterio de la mayoría acabe imponiéndose a la propia obra de arte. Subyace además una idea de deuda hacia el artista (el cantante): los que le seguían al principio dejan de seguirle, porque ya no les "representa" (no le deben ya nada).

En cualquier caso, el mercado pasa de ser un poder omnipotente - como en el caso de los chicos - a tomar el rostro de "los demás", de la demanda masiva, de la mayoría. Así pues, el origen de la perversión es para las chicas sobre todo la masificación que la mercantilización trae consigo (y no la conversión en mercancía como en el caso de los chicos).

La contraposición socialmente producida entre un arte puro o auténtico, un "arte por el arte" dirigido a un público restringido y que rechaza radicalmente el interés económico y el éxito temporal, y un arte comercial dirigido al gran público es constitutiva del campo artístico (y de los campos de producción cultural en general), así como la condición de su autonomía (Bourdieu, 1995: 318-330). En ambos grupos se asume esta oposición, aunque incidiendo en la crítica de distintas dimensiones del arte comercial. Así pues, en el caso de los chicos, parece consagrarse la creación como ámbito cuya "pureza" debe ser preservada por el artista — de ahí las denuncias a la mercantilización-, mientras que en el caso de las chicas se consagra la recepción de la obra como momento fundamental del proceso artístico — de ahí las denuncias a la masificación-.

\section{Contra las élites: entre el poder y la justicia}

En los discursos grupales se realizó una asociación entre arte y élite ${ }^{11}$. En general, las chicas le dieron más importancia a la élite en lo que concierne a los receptores de arte, mientras que los chicos subrayan la el carácter elitista de los artistas.

En el caso de las chicas se mostró acuerdo en que el arte está hecho "para" un público y en que debería ser "para todos". Doble acuerdo sobre el ser (restringido) y el deber ser (democrático) del arte, con el que se muestra de acuerdo el grupo entero:

Yo creo que el arte es para todo el mundo [...] yo creo que es para todo el mundo pero realmente no llega a todo el mundo, o sea, no llega, no llega. [...]

- Ahí es donde entra de lo que hablábamos antes, es que el arte se ha elitizado. O sea, lo que te costaba antes escuchar al pavo este tocando en el metro, no es lo que te cuesta ahora en verle en un concierto.

- No, pero no lo ha elitizado, se ha elitizado él. (GDM)

\footnotetext{
${ }^{11}$ El discurso dominante se corresponde con el discurso de las fracciones dominantes en el campo artístico. El artista de vanguardia se reserva el privilegio del arte puro, sin injerencias del público o del mercado (ambas dimensiones permanecen, como hemos visto, estrechamente relacionadas), y de estar por eso más allá del bien y del mal, a diferencia del artista popular, que es expulsado de su condición de artista (Bourdieu, 1995: 322-325).
} 
La restricción a un público que no incluye a "todos" es un elemento claro de consenso, aunque se establece diálogo para determinar a qué se debe esta restricción: el dinero, la capacidad o la voluntad. El uso de la expresión "no llega" es significativa de esta concepción de un arte para, que no puede prescindir del público, al que tiene que "llegar" de alguna forma; un arte concebido como una comunicación que, para ser completa, debe llegar a ser recibida por el otro.

Definen su posición respecto al público al que va dirigido el arte en base a la exclusión que ellas perciben. Así, se refieren a "círculos muy cerrados", a "un círculo social", al "mundo de la literatura", "este rollo de la literatura", el "mundo" o "mundillo del arte" ( $\mathrm{sic}$ ) a los que por una u otra cosa no pueden acceder (o hacerlo bajo una serie de condiciones). La "elitización" aparece como proceso y responsabilidad individual, más que como proceso general y necesario.

Si bien es cierto que aparecen distintos discursos sobre el proceso de conversión del arte en arte "elitista", los discursos se articulan en base a la idea de que este mundo pertenece a una élite ("esa élite intelectual", "una élite especializada", "los que tienen una capacidad elevada", sic). El mundo del arte traza una línea divisoria entre los que están dentro y los que están fuera: la oposición dentro-fuera que encontramos constantemente en los discursos grupales ("meterse en", "entrar" o "estar en la élite", sic) aparece como fruto de un proceso de privatización, en contra de una especie de democracia primitiva o ideal. Esta ruptura entre dentro y fuera tiene su correlato en la mención constante que hacen de los lugares en los que se expone arte: "museos", "exposiciones", el "cine", las "ocupas", "la Casa Encendida" o el "Círculo de Bellas Artes" (sic). Los espacios pueden ser más o menos abiertos, pero se considera que están acotados, aun cuando se desecha la idea de las restricciones económicas como principal obstáculo para entrar:

Yo creo que también lo que habéis dicho antes, que también, o sea, tú lo que has dicho antes es verdad, que hay sitios donde puedes ir con poco dinero a ver arte, o por ningún dinero, pero también es un círculo muy cerrado. $\mathrm{Y}$ también, lo que he dicho antes, culturalmente hablando que parece que solamente pueden ir los que tienen una capacidad, me repito, pero es lo que... capacidad intelectual un poco más elevada 0 que pertenezcan a un círculo social. (GDM)

El receptor como élite no es tan central en los discursos de los chicos, aunque aparece. Los chicos se centran más en que el arte "enfoca" o "representa" ( sic) a un grupo social, de lo cual derivan una relación entre la representación aquello que la obra representa - y el grupo representado:

Pero la mayor parte de la historia, el arte representaba las ideas o la ideología o las concepciones oficiales, digamos. Pero oficiales que representaban a lo mejor a un $5 \%$ de la población, porque la inmensa mayoría de la población no consumía arte. Pero con el inicio de la cultura de masas en el siglo XX, todo el mundo empieza a consumir arte. Bueno, arte o no arte, pero música, pintura y todo eso. (GDH)

Se establece una relación directa entre lo representado por el arte y el grupo social que lo consume. Se entiende así que con la cultura de masas el ideal democrático del acceso al arte puede cumplirse, al tiempo que el arte pasa a representar a todos los grupos sociales. En oposición al grupo de chicas, en el 
que el acceso al arte aparece acotado, en este caso el acceso al arte aparece abierto: "todo el mundo empieza a consumir arte" (sic). Es más, es para todo el mundo.

Si se habló de que los artistas constituían una élite, las chicas no incidieron tanto en este aspecto, mientras que los chicos pusieron un mayor énfasis en las élites artísticas que en las élites de consumidores de arte. En este sentido, se establece una relación entre el público consumidor de arte y la obra de arte:

Entonces es eso, que es como que esta élite intelectual hace movidas como para esa élite intelectual. Entonces nosotros... yo creo, que la sociedad en sí no se llega a dar cuenta de las nuevas vanguardias que hay en el arte porque no somos capaces de entenderlos, porque lo hacen para una élite especializada. (GDM)

Entonces seguimos pensando que hay una cosa que es consumo, que se puede llamar arte si nos ponemos a ser generosos, y otra cosa que es arte propiamente dicho, que incluye una élite por parte de quien la produce y también por parte de quien la consume. (GDH)

Si en el caso de las chicas se incidió más en el público, en el de los chicos, por el contrario, el tema de la élite de artistas cobró mayor importancia que el del público $^{12}$. De acuerdo con la metonimia de los lugares y la "pose" (sic) de los artistas, se afirma lo siguiente:

Es que, hoy en día, si quiero ver arte, voy a un museo. El problema es que en muchos museos no lo hay. O sea el problema es que el arte tiene un moco aquí pegao [hace de nuevo el gesto de pegarse algo en el pecho, varias reacciones]: el moco de "oye, que soy artista". (GDH)

Lo que se entiende como una afirmación lógica (el arte está en los museos) parece no cumplirse. Es más, se señala que el lugar por excelencia (legítimo) de exposición de arte, en muchos casos, no tiene obras de arte en su interior. En este caso la medalla, el reconocimiento, y no su obra, es lo que hace artista al artista: estar en un museo.

Entre los chicos se emplea la oposición arriba-abajo para calificar la relación del artista con el resto de las personas. Así, los artistas son "de clase alta", "nobles", "burgueses", etc. — discurso de nuevo marcado por la familiaridad de los sujetos con las ciencias sociales-. Como hemos señalado antes, para ellos la élite no tiene lugar tanto en el público, que está constituido por "consumidores", como entre los artistas. Para salvar esta distancia y mantener la relación entre el grupo que se representa en la obra y el que la consume, afirman que los artistas "miran abajo" (sic). Un ejemplo de esa contraposición sería el siguiente:

Haendel, que todos le podríamos poner como un prototipo de buen artista y gran artista, una de sus grandes inspiraciones no era irse a hablar con las musas, no era irse a hablar con intelectuales y tal, no: era

\footnotetext{
${ }^{12}$ Sin duda la diferente extensión e intensidad con que se abordan distintos temas en distintos grupos de discusión puede responder a la vez a factores más o menos aleatorios y a factores estructurales. En este caso, como veremos, creemos que puede encontrarse una relación entre este desarrollo temático y las formas de relación que hombres y mujeres producen y reproducen con el arte en función de sus distintas posiciones sociales (que les empujarían a identificarse en sus discursos con posiciones homólogas).
} 
irse a la taberna más cochambrosa que os podáis imaginar de Londres a comer Frankfurt, salchichas y a beber cerveza. $Y$ en el momento en el que él se estaba poniendo las botas, cosa que a él le encantaba, escuchaba ritmos populares. [...] El cogía su filtro de clase dominante y filtraba todas esas melodías populares y con ello sacaba por ejemplo el Aleluya, de Haendel, que luego servía para justificar el poder de la monarquía inglesa... (GDH)

En algún caso, llega a entenderse la relación entre estos colectivos como expolio: "Pero es que eso son los de arriba los que se van abajo a cogerlo de abajo" (GDH). Los artistas — arriba — producen la obra para los de abajo.

Hemos observado diferencias y similitudes en los discursos de chicos y chicas en cuanto a las élites, la masificación y la mercantilización, elementos que en los grupos se plantearon desde el ideal de democratización, resaltándose aspectos distintos. Las chicas parecían percibir la democratización en términos de justicia: hablan de "mundos" o "círculos" que al estar acotados están "privatizados", consideran justo que estos círculos se extiendan, perciben que todos deberían tener derecho a entrar en esos círculos. La justicia implica igualdad en el acceso, el bien común opuesto al privado. Pero, al mismo tiempo, señalan que la masificación hace que el arte se vuelva impuro, legitimando el arte como círculo restringido. Los chicos, por su parte, parecían percibir la democratización en términos de poder: distinguen los que están "arriba" de los que están "abajo", en un eje vertical. Consideran que el arte se hace desde "arriba" para que los de "abajo" lo consuman.

\section{RELACIÓN CON LA CULTURA Y FORMAS DE POSICIONARSE FRENTE AL ARTE EN HOMBRES Y MUJERES}

Si las posiciones frente al arte contemporáneo y las formas de "perversión del arte" que hemos analizado nos muestran las representaciones que tienen del arte y de sus relaciones con el mundo tanto las chicas como los chicos, resulta relevante abordar la cuestión de los tipos de relación que establecen los sujetos con el arte a través de las formas de posicionarse frente a él que se manifiestan de forma más o menos implícita en sus discursos ${ }^{13}$.

\section{Arte y expresión: un punto de partida}

Chicos y chicas coinciden en establecer una primera definición de arte en relación con la función de expresión del mismo, aunque muestran en esto diferencias. Los chicos optan por un acercamiento desde la abstracción, desde la referencia al todo:

\footnotetext{
${ }^{13}$ La relación que los agentes establecen con el arte o con la cultura (rapport à la culture) difiere según el modo de adquisición del capital cultural en la socialización y el grado de familiaridad con los objetos culturales que éste proporciona (Bourdieu, 2006 [1979]). La técnica empleada permite analizar algunas características de esta relación (la familiaridad, el reconocimiento), pero no permite seguir el proceso de adquisición del capital cultural en el que se produce dicha relación.
} 
Yo creo que el arte es una forma de expresión de todo aquello que en principio no podemos expresar de forma convencional y tenemos que sacarlo de una forma especial, una forma que no suele ser la usual. Es una forma de expresión, básicamente. (GDH)

En el caso de las chicas la aproximación pasa por el inventario de los géneros artísticos, es decir, por los campos diversos del arte, por las partes del todo. El arte aparece así desde el principio como plural para ellas:

- Bueno, para mí el arte engloba un montón de cosas. Desde la música, el teatro, el cine, la pintura...

-...escultura...

- Escultura...

- La arquitectura... [Silencio] Y formas también de expresión. O sea, arte también es, por ejemplo... ahora se ha puesto muy de moda el arte este, por ejemplo, de la peña que se desnuda y se pinta el cuerpo. Esto... también es una especie de arte. (GDM)

Si bien los grupos coinciden en partir de la expresión como núcleo fundamental de la definición de arte, la propia formulación de los chicos ("una forma de expresión") muestra una idea de fondo: el arte es uno; mientras que la de las chicas defiende desde el principio que el arte es plural ("engloba un montón de cosas"; "formas" de expresión). Esto es significativo de esta diferencia y de forma general, como veremos a continuación, de la relación que parecen manifestar chicos y chicas con el arte en sus discursos.

\section{Reconocimiento y familiaridad en la relación de los sujetos con el arte}

A lo largo de los grupos de discusión, las intervenciones de unas y otros muestran en general una relación de familiaridad diferente según las disciplinas artísticas y géneros de los que se habla, que en general difiere del grado de reconocimiento y legitimidad que se les otorga.

En primer lugar, encontramos en la pintura y las artes plásticas el tipo de arte que mayor reconocimiento merecía en los grupos de discusión realizados, como encarnación del arte mismo:

- Sí, pero está claro que arte, una pintura es arte, arte y tal.

- Eso sí es arte

- Eso sí es arte. Lo creo que lo subjetivo ya... ¿Es arte, este micrófono con el lazo? ¿Es arte esas gafas? ¿Es arte esta mesa? (GDM)

La pintura es arte, es incuestionable para ellas. Representa el arte en sí, el arte que es arte independientemente de lo que piense cada uno -lo subjetivo-. El resto (micrófono, gafas, mesa), aquello que resulta problemático incluir dentro del arte, aquello que no ha sido incorporado como arte legítimo en la socialización, sin embargo, no genera el mismo reconocimiento sin fisuras: es "subjetivo" (sic), depende de cada uno. Sin embargo, también se muestran más reflexivas al reconocer la excesiva centralidad de la pintura en las representaciones comunes sobre el arte: 
Pues yo creo que siempre que piensas en arte lo primero que te viene a la cabeza es la pintura, pero no tiene por qué ser sólo eso.

Es un tipo de educación, o sea, cuando nosotros entendemos arte [...] “¿Qué entiendes por arte?”. Pues a todo el mundo se nos pone en la cabeza: la pintura. (GDM)

En el caso de los chicos, sin embargo, aunque no manifiestan un reconocimiento tan manifiesto de la pintura como ámbito artístico por excelencia - foco de la crítica de relativismo ("A estas alturas ya todo es un cuadro")—, sí lo manifiestan en sus intervenciones, cuando oponen a los grandes, identificados con pintores como Velázquez (la referencia a Las Meninas es recurrente), Goya o Picasso, al resto.

Sin embargo, aunque ambos géneros reconozcan la pintura explícita o implícitamente como ámbito por excelencia del arte, sus intervenciones denotan una familiaridad mayor con otras disciplinas artísticas, como la música o el cine. Conforme se nombran en general pocas corrientes artísticas en pintura a diferencia de artistas u obras particulares que gozan de un reconocimiento "universal", en los grupos se tiende, en referencia a la música o el cine, a dar ejemplos más concretos y actuales, con los que parecen identificarse más y que no entrarían en la misma categoría que los citados en referencia a la pintura:

Todo el mundo nos íbamos a la plaza del Grial, íbamos a las ocupas, y escuchábamos y decíamos: "Uuu, Canteca de Macao, iqué alternativos!". (GDM)

Encontramos, además del recurso a un imaginario común a esta generación, la familiaridad de las participantes en el grupo con un tipo de música relacionado con sus prácticas habituales de ocio o su estilo de vida.

En el caso de los chicos, la familiaridad con el ámbito de la música aparece claramente cuando se preguntan por estilos musicales como el punk o el heavy:

- Pero es que eso... A lo mejor yo voy a un concierto de Non servium ${ }^{14}$ y voy allí y me doy las mayores hostias del mundo en el pogo ${ }^{15}$.

- Pero no es arte.

- Pero no es arte. Si quiero ver arte pues me voy a un concierto en el que se vaya a tocar una pieza de Beethoven. [...]

Si tú vas por la calle y preguntas si las sinfonías de Beethoven lo consideran arte, pues el $99 \%$ te dirá que sí. Pero luego a esas mismas personas les preguntas si lo que hace un grupo heavy, un nuevo grupo heavy que ha salido, es arte y la gran mayoría te va a decir que no, que eso no es arte, que eso es muy feo, suena mal y que eso no es arte. $(\mathrm{GDH})$

\footnotetext{
${ }^{14}$ Grupo madrileño de "Oi!", estilo musical derivado del punk y que toma su nombre de un saludo común a los miembros del movimiento punk británico nacido a finales de los años 70 .

${ }^{15}$ En la jerga juvenil rock, el "pogo" designa la práctica, común en conciertos de rock, de formar un círculo y lanzarse dentro del mismo a empujarse con otros, algo que sin embargo no tiene por qué degenerar en una violencia o brutalidad mayor, puesto que se realiza con intención de diversión y bajo un cierto control solidario.
} 
En este caso, además, encontramos una particular disonancia en lo que respecta a la inclusión o no de los estilos que les son más familiares a los participantes del grupo en la categoría de arte. Par ellos, por ejemplo, el grupo de punk Non servium (referencia común a la mayoría del grupo) no es arte -0 al menos puede ser debatido-, pero Beethoven lo es incuestionablemente. El gusto, entendido como algo subjetivo, de cada cual, es en sus discursos disociado del arte, que aparece como categoría objetiva, exclusiva, en la que no puede entrar "cualquier cosa" que guste. Así, paradójicamente, lo que les es familiar, lo que a ellos les gusta personalmente ve cuestionado su estatus artístico frente al arte legítimo y "universalmente" reconocido (Beethoven), y es relegado a una categoría "inferior" de menor valor.

Este mismo fenómeno lo encontramos cuando se habla sobre cine. Chicos y chicas coinciden en diferenciar, usando sus propios términos, entre el cine propiamente artístico y el cine de ocio o de entretenimiento.

- Bueno, Chaplin era un genio. No creo que nadie venga ahora a decirme que Charlie Chaplin era un payaso.

- Por eso. Es lo que quería decir, ¿sabes? Que no es lo mismo el humor de Chaplin que el de Disaster movie.

- No, no [confirma]. (GDH)

Yo, dentro del cine, tampoco lo describiría como arte todo. Porque es que a mí, por ejemplo, me ponen American Pie y yo no veo arte, ¿sabes?

Porque hay cine populary cine de autor. (GDM)

Los ejemplos escogidos, además, como paradigmáticos del cine que no puede ser considerado arte (Disaster Movie, Dos colgaos muy fumaos, American Pie) se refieren en los grupos a un mismo tipo de comedia (norteamericana, popular, destinada a un público joven) y que oponen — por acuerdo unánime en los grupos - al cine "propiamente artístico", asociado a la genialidad, la profundidad, al "cine de autor" (en oposición a "un argumento fácil de seguir", "no pensar nada en lo que visto, porque no hay nada que pensar", sic). Es significativo además el hecho de que se haga referencia a este tipo de cine "artístico" nombrando autores (Chaplin, Kubrick en chicos; David Lynch, Ken Loach en chicas) más que obras (como ocurre cuando se habla del cine de entretenimiento). A pesar de la familiaridad que denotan sus intervenciones con este tipo de cine popular, manifiestan hacia él una clara actitud de desdén, actitud más marcada en los chicos, reconociéndole únicamente una función de entretenimiento y situándolo en una categoría distinta y claramente inferior a la del arte.

La alodoxia cultural ${ }^{16}$ con respecto al arte legítimo, que reconocen, pero con el que muestran poca familiaridad, es común a los grupos y se manifiesta en varios ejemplos, particularmente en la inseguridad y los "errores" ${ }^{17}$ en los que

\footnotetext{
${ }^{16}$ Bourdieu la define en La distinción como aquellos "errores de identificación y [...] todas las formas de falso reconocimiento en que se pone de manifiesto la diferencia entre el conocimiento y el reconocimiento" (1988: 326$)$.

${ }^{17}$ Entendemos aquí por "errores" aquellas intervenciones que no se adecuan o se distancian manifiestamente del conocimiento socialmente establecido, de la cultura legítima en materia de arte. Nos interesan, por tanto, como indicadores de alodoxia o de una relación de poca
} 
incurren en sus intervenciones al recurrir a ejemplos. En el caso de las chicas es particularmente significativo el ejemplo de Saturno devorando a un hijo, de Francisco de Goya, o el del Musée D’Orsay de París:

- Vale, no lo ves tan claro, pero más o menos, ves a un tío que se está comiendo a un pavo. Pero eso, ves a un Cristo que se está comiendo, pues eso, un cuerpo. Que es lo que representa...

- En El fusilamiento del dos de mayo, sí.

- Saturno devorando a sus hijos.

- Sí, que no era un Cristo, sino el pavo ese. (GDM)

El Louvre, por ejemplo, también te cuesta tres pavos. Y el D'Orsay en Italia, también te cuesta. (GDM)

En los chicos también se dan varios ejemplos de alodoxia. Las siguientes intervenciones sobre Wagner y Mozart o Velázquez y Picasso son significativas de la reducida familiaridad con el arte reconocido:

Mozart se moría de hambre, Wagner era un don-nadie en Alemania en su momento.

Yo no creo que... yo que sé, Velázquez o Picasso, por seguir poniendo los mismos ejemplos, sean menos artistas porque no se les haya reconocido en vida. (GDH)

Sin embargo, destaca el hecho de que, en el discurso de los chicos, se da una tendencia más fuerte que en el de las chicas a mostrar posiciones tajantes y seguras, aún cuando los "errores" que cometen denotan desconocimiento del arte legítimo y poca familiaridad con el tema del que se habla (por ejemplo, al desconocimiento de la vida de los artistas se le busca una "compensación" con el recurso a estereotipos comunes como el del "artista no reconocido en vida", "incomprendido").

Encontramos, por tanto, en general una relación más familiar con aquellas disciplinas artísticas (música, cine) y en particular ciertos sectores dentro de ellas (estilos y grupos musicales, directores y películas de cine), sin por ello concederles una mayor legitimidad cultural. Al contrario, manifiestan en sus intervenciones un mayor reconocimiento hacia aquello que han incorporado como arte legítimo (la pintura, Van Gogh, Picasso, Velázquez, Goya) más que hacia aquello que les es cercano y que constituyen los bienes culturales que consumen, con los que se relacionan cotidianamente. Los participantes en los grupos se hacen portadores en sus discursos de una definición social del arte legítimo que les viene dada y que en buena medida parece encontrarse paradójicamente desligada de sus propias prácticas culturales cotidianas.

\section{La "originalidad” del artista: entre esencia y apariencia}

Otro de los aspectos que en los grupos se manifestaron como significativos de una relación distinta con el arte en hombres y mujeres fue la representación del

familiaridad y de distancia frente al arte legítimo (reconocido pero no necesariamente conocido), no como una supuesta muestra de ignorancia. 
artista que se mostraba en sus discursos. La forma de hablar sobre los artistas manifiesta una forma de situarse con respecto a ellos.

Por un lado, el grupo de chicos, más enfocado al artista y la producción de la obra, desarrolló especialmente el tema del "genio", lo que Nathalie Heinich llama el régimen de singularidad" ${ }^{18}$ (2001: 57), centrándose en la idea de los "virtuosos", los "grandes" y lo que les diferencia del resto:

Quiero decir, la diferencia entre Picasso o Velázquez, los grandes, y el Warhol es que los grandes digamos que tienen un don, o sea es el don del arte: sabían hacer lo que sabían hacer bien hecho. ${ }^{19}$

No, no, no. Pero yo me refiero a los virtuosos de la música. Joder, eso... [...] hay que tenerlos cuadraos para saber hacer eso, ¿sabes? (GDH)

En los discursos analizados, el artista aparece siempre como masculino y el "don", la "virtud", lo que le diferencia del resto, en ocasiones aparece además como atributo viril ("hay que tenerlos cuadraos"). Asimismo, el término "don" aunque se utilice la palabra manifiestamente como algo provisional, a falta de un término mejor - se disocia de los conocimientos técnicos:

No sé, yo creo que hay una técnica, pero ni necesariamente tienes que tener unos conocimientos técnicos, ni por tener unos conocimientos técnicos estás haciendo arte. Tú puedes haber estado estudiando arte durante años y que tus cuadros sean horribles, que sean una mierda. $Y$ lo mismo pasa con la música: hay gente que toca en bandas, que... no de música clásica, de música ligera, y no saben lo que es un La. Sencillamente saben tocar muy bien las cuerdas. Nada más. (GDH)

El músico que "toca muy bien" sin tener conocimientos de lenguaje o teoría musical es un mito muy común: sin saber música es capaz de hacerla. Como en el mito del músico autodidacta, se obvia el proceso que permite desarrollar esa competencia musical: "sencillamente" (sic) sabe, el cómo se pierde y el don ocupa el lugar de la causa que lo explica. El artista tendría así "algo", más allá de conocimientos o capacidades aprendidas, que le haría diferente y único.

Las chicas, sin embargo, menos centradas en el artista y la producción que en la recepción y el público receptor, se posicionaron de forma distinta con respecto a la figura del artista: "Cada uno tenemos un artista dentro" (sic). Según ellas, cualquier persona es un artista en potencia en la medida en que tiene algo "dentro", sentimientos que expresar. El elemento fundamental no es una propiedad mágica (don) como en el caso de los chicos; la condición que posibilita el arte según el grupo de chicas es la subjetividad, el mundo de la interioridad, de los sentimientos, para los que el arte sirve de vía de salida ${ }^{20}$.

${ }^{18}$ Un "régimen específico de valorización" que aparece "cuando las calificaciones puestas en práctica espontáneamente por los actores privilegian la unicidad, la originalidad, la anormalidad - siendo este "régimen de singularidad" el del arte en la época moderna" (Heinich, 2001: 57).

${ }^{19}$ El carácter tautológico de esta definición espontánea del don resulta significativo de la dificultad (véase imposibilidad) de definir tal concepto. La reiteración del verbo "hacer" en distintas formas sitúa la producción - con conocimiento (saber hacer) y con habilidad (hacer bien) - en el centro de la actividad creadora del artista.

${ }^{20}$ Como señala Mayayo: "Implicarse personalmente en el ejercicio de la crítica supone, por supuesto, abandonar un modelo interpretativo basado exclusivamente en la reflexión intelectual: arte y vida se confunden; el cuerpo, las emociones y los deseos pasan a formar parte del acto de contemplación artística" (2003: 106-107). Este último tipo de contemplación 
Este discurso aparece también en los chicos, pero no suscita un consenso unánime: se matiza enseguida cada vez que sale, se impide su desarrollo recurriendo a otros temas (los conocimientos técnicos, el "don", etc.). En el caso de las chicas también se matiza la proposición "Cada uno tenemos un artista dentro": tiene que haber algo que distinga al artista del resto y para ellas es el hecho de "ser original" ( $\operatorname{sic}$ ).

Tanto en el caso de los chicos como en el de las chicas encontramos, por tanto, formas de explicar su propia posición profana con respecto a la categoría de artista recurriendo al registro de la originalidad y la singularidad del artista (que es artista porque "algo" le hace diferente ${ }^{21}$ ), que funciona como un discurso autoexcluyente y legitimador de la posición privilegiada del artista.

\section{Arte sin espectador: el lugar del receptor}

Otro elemento que nos parece relevante analizar como manifestación de un tipo de relación con el arte distinto en chicos y chicas es la forma que ambos tienen de representarse la importancia del receptor, en la definición de lo que es o no arte.

En el caso de los chicos esta cuestión sale a relucir hablando del problema del reconocimiento del artista por la sociedad, mientras que en el de chicas surge cuando discuten sobre la posibilidad de entender las obras. Encontramos en los grupos la idea de un arte separado del espectador, ya se trate de la sociedad (GDH) o del individuo (GDM):

Yo no creo que... yo que sé, Velázquez o Picasso, por seguir poniendo los mismos ejemplos, sean menos artistas porque no se les haya reconocido en vida. O sea, el problema de la sociedad es problema de la sociedad, no de los artistas. (GDH)

David Lynch está ahí y... él hace sus películas, si las quieres entender las entiendes y si no es tu problema. (GDM)

El arte "está ahí" independientemente de que tenga público o no, de que sea reconocido por la sociedad o por cualquier receptor individual. Se reconoce un "problema" en esta separación arte-espectador: para las chicas aparece como un problema del sujeto receptor, que no quiere o no puede comprender la obra, mientras que para los chicos parece tratarse de un problema de la sociedad, que no sabe reconocer al artista. En ambos casos el efecto es la legitimación de la posición privilegiada del arte y el artista, aunque significativamente los chicos parecen identificarse implícitamente con la posición del artista y las chicas con la del público receptor.

artística vinculada al cuerpo y las emociones se corresponde más con el tipo de recepción que traslucen los discursos de las chicas en nuestra investigación, que el modelo "intelectivo" aunque también está presente.

${ }^{21}$ Enseguida matizan esta idea de originalidad denunciando de forma unánime la posición del artista que basa dicha originalidad en una "pose" (sic), en una apariencia, una fachada. Esta crítica de la superficialidad y el aparentar (el cinismo) en el mundo del arte es recurrente en el caso de las chicas y apenas aparece en el caso de los chicos. El artista es criticado por su excentricidad, por dar una imagen falsa o exagerada que no se corresponde con un fondo realmente artístico. 


\section{Público y obra: la cuestión de la recepción}

La cuestión de la relación arte-espectador lleva a la cuestión de la recepción del arte. Si bien se llega, como hemos visto, hasta el extremo de enunciar la posibilidad de un arte sin espectador, este tema es más desarrollado por los chicos puesto que se centran más en la cuestión de la producción y en los criterios para ser artista.

En los grupos se recurre a la idea de expresión para tratar la cuestión de la recepción: el arte consigue expresar algo a su receptor, conectar con él. La recepción del arte implica una conexión de la obra con la subjetividad, con lo que el receptor tiene "dentro". Tiene una dimensión corporal, fisiológica, va más allá de la razón. Sin embargo, este discurso, que da importancia al receptor como sujeto, es rápidamente interrumpido en el caso de los chicos:

- [...] Para mí el arte sencillamente es todo aquello que a mí consigue expresarme algo o moverme algo dentro [...] lo que consigue conectar lo que el autor a lo mejor ni siquiera ha querido expresar, pero consigue conectar la obra con algo que tengo yo.

- Ya, pero hay cosas que te dicen algo y me reconocerás que tú admites que eso no es arte. (GDH)

Admiten así la conexión de la obra con la subjetividad de cada uno, pero se resisten a considerarlo como criterio definitorio del arte: que exprese algo a alguien, que "conecte" de alguna forma con el sujeto no basta. Para ellos, el sujeto-receptor no define el arte, porque el arte es externo a él y se define por criterios que van más allá de su subjetividad y sus sentimientos. La subjetividad es para ellos más importante en el otro extremo del proceso: en la creación, en la producción de la obra.

Sin embargo, en el caso de las chicas el papel del sujeto en la recepción vuelve continuamente, con el uso recurrente y constante a lo largo de toda la conversación del verbo "expresar" en su forma reflexiva, incluyendo un pronombre que designa al sujeto-receptor del arte (no al artista): "expresarme", "me expresa", "te expresa", añadiéndosele en algunos casos un pronombre suplementario y reiterativo ("te expresa a $t i$ ", "me expresa a mi"), redundancia significativa de esa importancia dada al sujeto.

Esta centralidad del sujeto-receptor es desarrollada por las chicas hablando más concretamente de la identificación con la obra, a la que asocian diversos sentidos o formas de relacionarse con ella:

- Fusión personal con la obra ("te haces una con", "pasa a formar parte de ti").

- Selección o atracción personal por partes o elementos particulares de la obra ("me identifico más con colores, [...] con movimientos", "coges de cada cosa donde más te identificas").

- Correspondencia o adecuación con la personalidad de cada uno ("todo lo que la música que escuches, lo que lees, la obra de teatro [...] va relacionado con tu forma de pensar, de ser, de actuar", "Sí, sí, sí. Con la personalidad que tú has adquirido a lo largo de tu vida").

- Relación con experiencias personales. Es especialmente significativo el hecho de que el ejemplo central sobre el que gira este argumento en el discurso de las chicas sea el de la canción que recuerda una relación amorosa ("la típica canción que tienes con tu novio"). 
Estos cuatro tipos ideales de relación con la obra muestran una concepción subyacente de esta relación: cada sujeto mantiene una relación personal y única con cada obra de arte. Pero, además, el hecho de que la obra conecte emocionalmente con el receptor puede tener que ver con un estado de ánimo variable y relativo al momento concreto de la recepción:

Yo creo que sí que es importante, pero que tampoco tiene que ver con lo que hayas vivido antes. No sé. Yo, por ejemplo, el otro día, en Moncloa hay un tío, bueno, en Cuatro Caminos hay un tío que se pone a tocar el violín y vas bajando, es un trasbordo increíble y a mí el violín no me gusta, pero estaba ahí supercansada, tal, el tío tocando el violín y era como “¡Hostia, qué jefe eres tocando el violín!”. Y ves, a mí eso me transmitió, y no conozco a nadie que toque el violín ni estoy vinculada a nadie que toque el violín, pero para mí... (GDM)

Este ejemplo ilustra bien lo que podríamos llamar recepción corporal-afectiva, aquella en la que la obra se impone a los sentidos y suscita una reacción incluso cuando no se trata de una situación prevista de percepción estética, en función del estado de ánimo del sujeto en el momento de contacto con la obra.

En el caso de los chicos, sin embargo, la referencia al papel de la subjetividad en la recepción apenas se trata. Aparece oculto bajo una recepción que presentan más como una apreciación razonada de las formas y de la excelencia técnica que como reacción emocional (aunque algo de ello se manifieste en sus expresiones):

O sea, yo he visto en Príncipe Pío, o sea desde Príncipe Pío hasta Aravaca, [...] hay unos graffitis de la hostia. Pero de la hostia, o sea que dices "¿Cómo coño has hecho eso con cuatro botes de spray, sabes?". Increíbles, eh.

Entonces, ¿qué es arte? Lo que entiende la gente por... ¿lo que está en un museo es arte? ¿O lo que vemos cotidianamente de la expresión más pura del sentimiento más espontáneo del tío más tonto del mundo? Que, ¡hostias! Coges, lo ves y dices: "Me cago en la puta, este tío cuando lo hizo estaba pensando en esto". (GDH)

Estas dos intervenciones no hacen sino reforzar esta evasión de la subjetividad que se da en el caso de los chicos. Aun cuando la reacción parece relacionada con la subjetividad, con lo emocional, se mitiga esta dimensión interpretando esta reacción desde el modelo racional. En el caso de los chicos, no se dan referencias a la recepción en sí o a la relación concreta entre obra y receptor. Tienden más bien a emitir juicios tajantes, sin lugar a discusión y con pretensión de objetividad sobre las obras de arte ("es una mierda", etc.). El margen de interpretación que las chicas dan a cada sujeto en materia de arte ("cada uno interpreta el arte de una manera", "que a la hora de la verdad es un elemento totalmente subjetivo de la persona que lo mira", sic) tiende a desaparecer en el discurso de los chicos: no es el sujeto el que contiene la clave para juzgar la obra, sino la obra misma (sobre todo por sus propiedades formales) $)^{22}$.

\footnotetext{
${ }^{22}$ La diferencia y variabilidad de las interpretaciones del valor de una misma obra por sujetos distintos sólo aparece en el grupo de chicos cuando estos juicios absolutos entran en colisión
} 


\section{La “idea” en/detrás de la obra}

Sin embargo, conviene, para evitar una asociación demasiado forzada entre feminidad, subjetividad e irracionalidad, por un lado, y masculinidad, objetividad y racionalidad, resaltar que también ellas muestran en sus discursos una tendencia a concebir la recepción de la obra desde lo que Mayayo llama un "modelo interpretativo basado en la reflexión intelectual" (2003: 106), modelo dominante y androcéntrico. Ello se ve cuando se refieren en sus discursos a la cuestión del arte contemporáneo o el arte difícilmente accesible a la comprensión (como en el ejemplo del cine de David Lynch):

Yo afortunadamente fui con mi padre al cine, estaba en el cine diciendo: 'Me va a dar algo'... Mulholland Drive no, en otra supervieja suya... Salí y luego te explica la película, y es verdad: jestá muy claro! (GDM)

Sin embargo, este uso del modelo de interpretación racional o intelectual aparece en el caso de las chicas, a diferencia del caso de los chicos, unido a una cierta pasividad o incapacidad del sujeto para descifrar el sentido de la obra si no es gracias a una clave que le viene dada desde fuera por otros sujetos o que tiene que buscar el receptor contraponiendo interpretaciones ajenas ("me metí en foros para entenderlo", "cuando la piba me lo explicó, dije: ‘¡Hostia!', ¿sabes?, ‘ipues tiene razón!”’).

Aunque en los grupos se comparte la idea de que el arte expresa algo, una "idea", un "mensaje", el lugar que ocupan éstos en la relación obra-espectador varía entre los discursos de chicos y chicas. Para las chicas, la obra no parece tener por sí sola significado, pero el discurso que tiene detrás, que aparece condensado en la obra, es lo importante. Según esta visión, el espectador tiene que descifrar la obra. Como hemos señalado, son terceras instancias autorizadas ("el artista", "una amiga mía [que] estudió historia del arte", "mi padre", sic) las que ofrecen ayuda para descifrar el contenido. Sin embargo, por otro lado, los chicos no parecen conferir autoridad a terceras personas. Al contrario, la obra tiene que señalar la idea, debe bastarse por sí misma:

Bueno, pero no cualquier cosa es arte. Tú tienes una idea y si no has adquirido previamente unas cualificaciones ya sea en música, ya sea en pintura, ya sea en lo que sea, por mucho que tengas esa idea, no tienes forma de expresarla en forma de arte, digamos. (GDH)

Si no se expresa la "idea" "en forma de arte", no es arte.

Vemos, por tanto, que si los chicos consideran que las ideas y sentimientos están contenidos y expresados en la obra, las chicas consideran que las ideas y sentimientos están detrás de la obra y exigen una actividad para acceder a ellos: entender la obra exige un ejercicio activo de búsqueda de esa idea que está detrás.

Esto enlaza con la importancia que dan a los aspectos subjetivo y objetivo, de acuerdo con los lugares distintos que ocupa la idea "en" o "detrás de" la obra. En el caso de las chicas, entender la idea de la obra aparece como parte de la experiencia personal-subjetiva, se establece a través de una comunicación

sobre un ejemplo concreto. El conflicto en la valoración de un autor lleva a los participantes a relativizar sus posiciones. 
entre sujetos. Esto hace que legitimen más las instancias autorizadas, que hacen posible descifrar la obra.

Por el contrario, los chicos entienden que la idea está comprendida "en" la obra misma, se desliga de lo convencional —lo cotidiano-, es algo que sale de "dentro" del artista. A pesar de su origen subjetivo, tiene que objetivarse en la obra para que ésta se baste a sí misma. La objetivación tiene lugar a través de las cualificaciones. Las "cualificaciones" previamente adquiridas son la condición, en el discurso de los chicos -y en contradicción con la ideología del don que manifestaban antes-, de la correcta objetivación (propiamente artística) de esa realidad subjetiva. Los chicos legitiman así el saber establecido (la cultura legítima) en materia de arte y el sistema de "cualificaciones" que lo sanciona.

La visión de una recepción y apreciación intelectual y razonada de las obras no es por tanto monopolio de los chicos. Las chicas también recurren a ella. Sin embargo, se deja de lado conforme se desarrolla la conversación hacia las formas de arte que les resultan más cercanas. Además, los chicos, como hemos visto, también dan pistas implícitas de una recepción de carácter subjetivo y emocional, pese a evitar el tema y resistirse durante toda la discusión a admitir este tipo de relación subjetiva con el arte. Se trata, por tanto, de diferencias sutiles de intensidad y actitud, y de una concepción del arte y de la relación entre la obra y el receptor (mediada o no por instancias, referida a un "mensaje", etc.) implícita en sus discursos sobre el arte.

\section{CONCLUSIONES}

No sería justo quedarse únicamente con las diferencias en las representaciones entre hombres y mujeres sin matizar dos aspectos relevantes que nos hemos encontrado en el desarrollo del estudio: en primer lugar, que el universo simbólico al que se refieren los sujetos es común a ambos grupos; y en segundo lugar, que las diferencias entre ambos parecen más diferencias de intensidad o grado que diferencias radicales o, menos aún, de "naturaleza".

Tanto hombres como mujeres parten de un universo simbólico común, que se manifiesta tanto en los temas que escogen, los artistas y las obras que citan, como en la serie de oposiciones que articulan sus discursos y que tienden a reforzarse mutuamente (arte contemporáneo-arte clásico, arte puro-arte comercial, arte-mercado, élite-masa, artista-público, arriba-abajo, dentro-fuera, calidad-cantidad, etc.; ver esquema a continuación). Pero también lo hace en algunos aspectos de la relación con el arte que implícitamente manifiestan en ellos. Es el caso de la alodoxia cultural y el paradójico reconocimiento del arte legítimo, poco familiar para ellos, al precio de la devaluación del arte más cercano a sus prácticas culturales cotidianas y estilos de vida, al que a veces ni siquiera reconocen el estatuto de arte. Inversión que podemos aventurar resultado de la incorporación de esquemas de percepción y apreciación del arte y la cultura -y en particular de jerarquías culturales - que les son en buena medida ajenos e impuestos. 


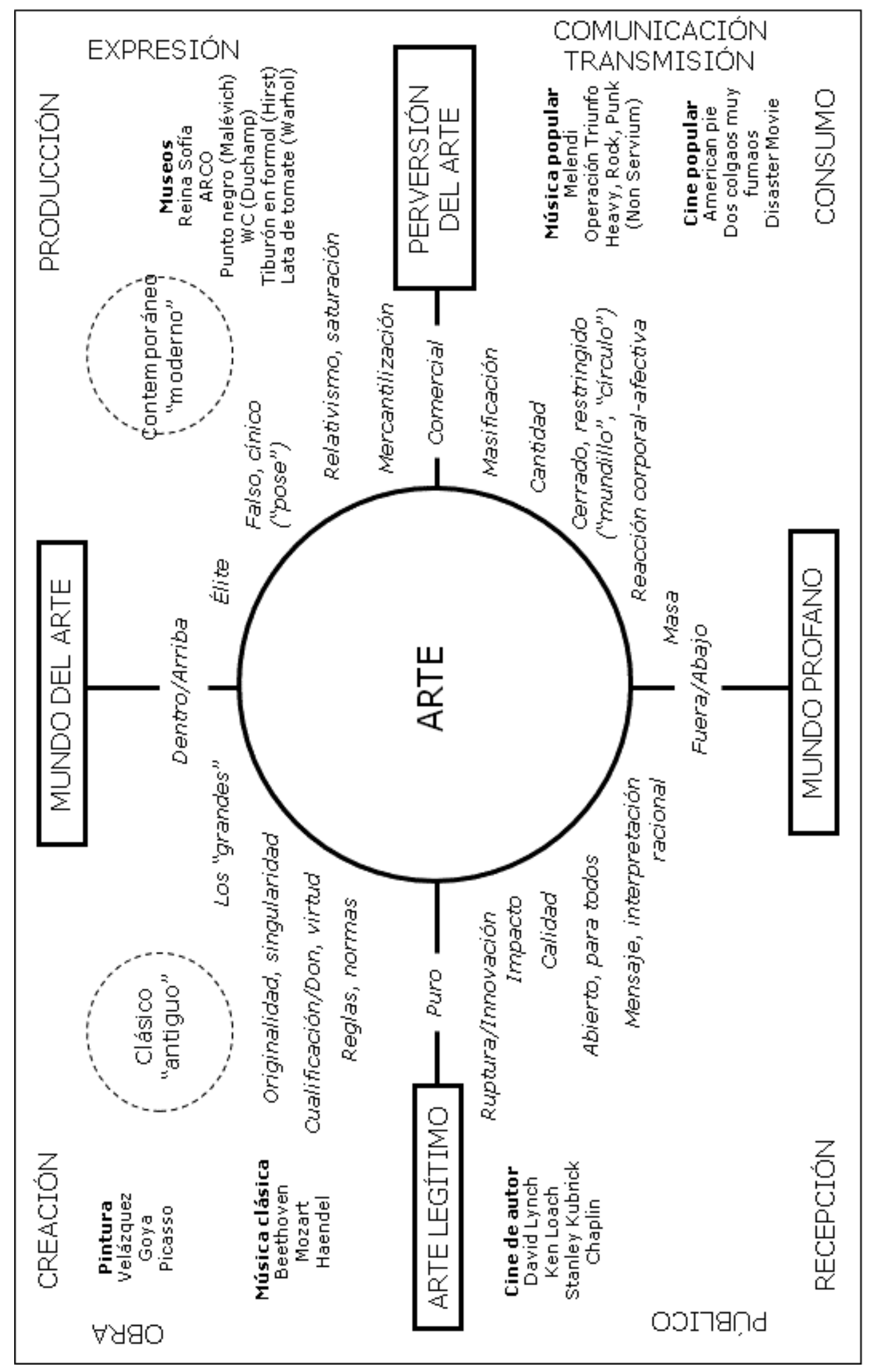


Si comparten ese universo simbólico es en parte, como hemos visto, porque ocupan una posición social similar en tanto que jóvenes estudiantes universitarios de ciencias sociales procedentes principalmente de las clases medias. Más que en un campo específico, el género estaría disperso y estructurado a lo largo del espacio social, rearticulándose de manera compleja dentro de cada uno de los campos, clases y fracciones de clase (Adkins, 2004: 6; McNay, 1999: 112), pero conservando también cierta especificidad con "la persistencia de ciertas normas simbólicas dentro de la diversidad de comportamientos masculinos y femeninos" (McNay, 1999: 112). De ahí que aun compartiendo una posición social común (jóvenes estudiantes universitarios de clase media), sus discursos sobre el arte cuenten con diferencias atribuibles en parte a una socialización diferencial en cuanto al género.

Se hace difícil, sin embargo, la distinción entre dos discursos radicalmente opuestos e internamente homogéneos en función del género, cediendo a la tentación de construir bloques monolíticos —con el consiguiente riesgo de reproducir los estereotipos de género y las dicotomías dominantes-. Al contrario, los discursos con que nos encontramos durante toda la investigación fueron en su mayoría comunes a hombres y mujeres y sólo difirieron en detalles de fondo, grados de intensidad e insistencia en ciertos puntos, y formas de posicionarse significativas de un tipo de relación con el arte. Por ejemplo: la mayor centralidad en los discursos de los chicos de la producción artística y los productores-artistas, frente a la centralidad de la recepción y el público-receptor en la chicas, producto de una identificación implícita y respectiva con dichas posiciones (siguiendo lo que Bourdieu denomina una homología estructura/23); el mayor peso e insistencia otorgado a la subjetividad en la producción y recepción artística en el caso de las chicas, tema presente pero interrumpido y evitado en los chicos; la correlativa insistencia, mayor en las primeras y menor en los últimos, en un modelo corporal-afectivo de recepción del arte frente a otro racional-intelectivo; o las formas distintas de entender la comprensión de la obra de arte (la lectura del mensaje en la obra misma, en los chicos, acompañada de una actitud tajante y formalista en el enjuiciamiento de las obras; la búsqueda del mensaje "detrás" de la obra, con ayuda de terceros autorizados, en las chicas, acompañada de una relativización de los juicios y una mayor permisividad en cuanto a las formas).

Convendría, no obstante, contrastar los resultados de la presente investigación, de carácter exploratorio, incluyendo un mayor número de grupos de discusión y de sectores de la población para ver en qué medida este universo simbólico común y estas diferencias entre hombres y mujeres pueden llegar o no a encontrarse en otros estratos sociales y clases de edad, así como en el conjunto de agentes implicados más directamente en el campo artístico (artistas, galeristas, críticos, estudiantes de arte, etc.).

Proseguir la investigación en esta y otras líneas permitiría sin duda seguir avanzando en la comprensión de las estructuras de percepción y apreciación

\footnotetext{
${ }^{23}$ Esta tendencia viene a evidenciar el problema de la doble segregación que señalábamos al principio de este artículo: las mujeres tendieron a identificarse más con la posición del público, en correspondencia con el mayor interés que muestran por el arte; mientras que los hombres tendieron a identificarse con la posición del artista, en correspondencia con el carácter más bien masculinizado de la práctica artística profesionalizada e institucionalmente reconocida.
} 
incorporadas por los agentes en materia de arte, contribuyendo así a una mejor comprensión de las desigualdades de hombres y mujeres en el mundo del arte y la cultura y de los complejos mecanismos que contribuyen a su reproducción.

\section{BIBLIOGRAFÍA}

AAVC (2006): La dimensión económica de las artes visuales en España, Barcelona: AAVC [en línea]. Disponible en Web: http://www.aavc.net/aavc net/html/documents/deave/deave-all.pdf

ADKINS, Lisa (2004): "Introduction: Feminism, Bourdieu and after" en ADKINS, Lisa y SKEGGS, Beverley (eds.): Feminism after Bourdieu, Oxford, UK: Blackwell, 2004, pp. 4-18.

BENJAMIN, Walter (1973 [1935]): La obra de arte en la época de su reproductibilidad técnica, Madrid: Tecnos.

BERGER, Peter L. y LUCKMANN, Thomas (2006 [1967]): La construcción social de la realidad, Buenos Aires: Amorrortu.

BOURDIEU, Pierre (2006 [1979]): La distinción. Criterio y bases sociales del gusto, Taurus, Madrid.

BOURDIEU, Pierre (1995 [1992]): Las reglas del arte. Génesis y estructura del campo literario, Barcelona: Anagrama.

BOURDIEU, Pierre (1998): La domination masculine, París: Editions du Seuil.

CALLEJO, Javier (2001): El grupo de discusión: introducción a una práctica investigadora, Barcelona: Ariel, col. Practicum.

HARDING, Sandra (1986): The science question in feminism, Ithaca, New York: Cornell University Press.

HEINICH, Nathalie (2003): La sociologie de l'art, París: La Découverte.

IBÁÑEZ, Jesús (2003 [1979]): Más allá de la sociología, Madrid: Siglo XXI.

INJUVE (2007): Sondeo de opinión. 2 $2^{a}$ encuesta 2007. Tablas de resultados. Uso de Tecnologías, Ocio y Tiempo Libre e Información [última consulta: 3 de enero de 2012]. Disponible en Web: http://injuve.es/injuve/contenidos.downloadatt.action?id=1731355799

MAV (s.f.): La igualdad en cifras [última consulta: 3 de enero de 2012]. Disponible en Web: http://www.mav.org.es/index.php?option=com content\&view=article\&id=50\&lte mid=63

MAYAYO, Patricia (2003): Historia de mujeres, historia del arte, Madrid: Cátedra.

MCNAY, Lois (1999): "Gender, Habitus and the Field. Pierre Bourdieu and the Limits of Reflexivitiy", Theory, Culture \& Society, 1999, Vol. 16(1): 95-117.

MEYER, Irene (2001): "Construcción de la subjetividad en la familia posmoderna. Un ensayo prospectivo", en BURIN, Mabel y MEYER, Irene: Género y familia. Poder, amor y sexualidad en la construcción de la subjetividad, Buenos Aires: Paidós. 